\title{
Prevalência da associação entre lesões cervicais não cariosas e estresse em pacientes da Clínica de Odontologia da UFCG em 2019
}

Prevalence of the association between noncarious cervical lesions and stress in patients of the UFCG Odontology Clinic at 2019 Prevalencia de asociación entre lesiones cervicales no cariosas y estrés en pacientes de la Clínica de Odontología UFCG en 2019 Dayse Rosângela Mendes Pires FRAGA ${ }^{1}$ José Henrique de Araújo $\mathbf{C R U Z}^{\mathbf{1}}$

Debora Lorrany Rocha de CARVALHO Abrahão Alves de OLIVEIRA FILHO²

Maria Angélica Satyro Gomes ALVES ${ }^{2}$

Camila Helena Machado da Costa FIGUEIREDO² Elizandra Silva da PENHA ${ }^{2}$

Luanna Abílio Diniz Melquíades de MEDEIROS ${ }^{2}$ Gymenna Maria Tenório GUÊNES ${ }^{2}$

${ }^{1}$ Cirurgiã(o)-Dentista pelo Curso de Graduação em Odontologia, Centro de Saúde e Tecnologia Rural, Universidade Federal de Campina Grande (UFCG) 58708-110 Patos - PB, Brasil

${ }^{2}$ Professor(a) Doutor(a), Curso de Graduação em Odontologia, Centro de Saúde e Tecnologia Rural, Universidade Federal de Campina Grande (UFCG) 58708-110 Patos - PB, Brasil

\section{Resumo}

As lesões cervicais não cariosas (LCNC) apresentam-se como perda irreversível da estrutura dentária na região cervical sem envolvimento bacteriano, possuindo etiologia complexa e multifatorial. Associada ao estresse, essa perda de tecido tem sido compreendida por fatores oclusais, associando a lesão ao bruxismo, apertamento e contato prematuro. Este trabalho objetivou comparar os níveis de estresse nos pacientes atendidos na Clínica Escola de Odontologia da UFCG e que apresentavam ou não LCNC. O estudo adotou como estratégia a coleta de dados o questionário de Sintomas de Estresse de Lipp (ISSL). Nesse questionário a fase I corresponde à experiência de estresse nas ultimas 24 horas, a fase II na última semana e a fase III no último mês. Os dados foram coletados de Março a Maio de 2019 e o mesmo foi aprovado pelo CEP. A amostra foi composta por 151 participantes, $100(66,2 \%)$ foram mulheres e $51(33,8 \%)$ homens, dos quais, $26(50,9 \%)$ apresentavam-se em fase de exaustão (Fase III), e de 100 mulheres, 52 (52\%) também se encontravam nesse nível. Quando questionados sobre o sistema estomatognático, boca seca foi a mais relatada entre os homens $(56,7 \%)$ e mulheres $(35,7 \%)$ sem LCNC. Já entre as mulheres com essas lesões, tensão muscular foi a mais assinalada (50\%). Portanto, o estresse pode propiciar o surgimento de desordens no aparelho estomatognático.

Descritores: Odontologia; Dentística Operatória; Erosão Dentária; Abrasão Dentária.

\section{Abstract}

Noncarious cervical lesions (LCNC) present as irreversible loss of dental structure in the cervical region without bacterial involvement, having a complex and multifactorial etiology. Associated with stress, the loss of dental tissue in this region has been understood by occlusal factors, associating the lesion with bruxism, tightening and premature contact, and is associated with dietary, parafunctional habits, time of the teeth in the mouth and greater attempt of hygiene. This study aimed to compare the stress levels in the patients attended at the Clinical School of Dentistry of the UFCG and who presented or not LCNC. The study adopted as strategy the data collection of the Lipp Stress Symptoms questionnaire (ISSL). In this questionnaire phase I corresponds to the experience of stress in the last 24 hours, phase II in the last week and phase III in the last month. The data were collected from March to May 2019 and the same was approved by the CEP. The sample consisted of 151 participants, 100 $(66.2 \%)$ were women and $51(33.8 \%)$ men, of whom, $26(50.9 \%)$ were in the phase of exhaustion (Phase III), and of 100 women, $52(52 \%)$ were also at that level. When asked about the stomatognathic system, dry mouth was the most reported among men (56.7\%) and women (35.7\%) without LCNC. Among the women with these lesions, muscle tension was the most marked (50\%). Therefore, stress can lead to the appearance of disorders in the stomatognathic apparatus.

Descriptors: Dentistry; Dentistry, Operative; Tooth Erosion; Tooth Abrasion.

\section{Resumen}

Las lesiones cervicales no cariosas (LCNC) se presentan como pérdida irreversible de la estructura dental en la región cervical sin implicación bacteriana, con etiología compleja y multifactorial. La pérdida de tejido dental en esta región ha sido comprendida por factores oclusales, asociando la lesión al bruxismo, aprieto y contacto prematuro, y está asociada a hábitos dietéticos, para-funcionales, tiempo de los dientes en boca e intento mayor de higiene. Este trabajo objetivó comparar los niveles de estrés en los pacientes atendidos en la Clínica Escuela de Odontología de la UFCG y que presentaban o no LCNC. El estudio adoptó como estrategia la recolección de datos el cuestionario de Síntomas de estrés de Lipp (ISSL). En este cuestionario la fase I corresponde a la experiencia de estrés en las últimas 24 horas, la fase II en la última semana y la fase III en el último mes. Los datos fueron recolectados de marzo a mayo de 2019 y el mismo fue aprobado por el CEP. La muestra fue compuesta por 151 participantes, $100(66,2 \%)$ fueron mujeres y $51(33,8 \%)$ hombres, de los cuales, 26 (50,9\%) se presentaban en fase de agotamiento (Fase III), y de 100 mujeres, 52 (52\%) también se encontraban en ese nivel. Cuando se les preguntó sobre el sistema estomatognático, la boca seca fue la más reportada entre los hombres (56,7\%) y mujeres (35,7\%) sin LCNC. Ya entre las mujeres con esas lesiones, la tensión muscular fue la más marcada (50\%). Por lo tanto, el estrés puede propiciar el surgimiento de desórdenes en el aparato estomatognático.

Descriptores: Odontología; Operatória Dental; Erosión de los Dientes; Abrasión de los Dientes.

INTRODUÇÃO

\section{As lesões cervicais não cariosas} apresentam-se como uma perda irreversível da estrutura dentária na região cervical sem 0 envolvimento da ação de bactérias e possui etiologia complexa e multifatorial ${ }^{1}$. De acordo com a sua origem e as características clínica das lesões cervicais não cariosas são classificadas em erosão, abrasão e abfração ${ }^{2,3}$. A prevalência das lesões cervicais não cariosas tem aumentado cada vez mais devido a diversos fatores, como hábitos dietéticos, tempo dos dentes em boca, tentativa maior de higiene dos dentes e hábitos parafuncionais ${ }^{4}$.

Nesse raciocínio, nos diversos 
segmentos da sociedade, em virtude das exigências sociais modernas, o estresse tem aumentado na vida das pessoas, podendo ser constatado em todos os âmbitos ${ }^{5}$. Ele é caracterizado como um conjunto de perturbações orgânicas e/ou psíquicas, provocadas por vários estímulos ou agentes agressores, forçando o organismo a reagir, de modo a manter a homeostase interna ${ }^{6,7}$.

Em função do estresse, a perda de tecido dental na região cervical tem sido compreendida por diversos motivos, como o fator oclusal, que ocorre flexão na região cervical, comprovando a associação da lesão ao bruxismo, apertamento e contato prematuro ${ }^{8}$, e - estado psicológico do paciente como a frustração e ansiedade, estando intimamente relacionado ao bruxismo ${ }^{9}$.

Por outro lado, a qualidade de vida é a noção eminentemente humana, relacionada ao grau de satisfação encontrado na vida familiar, amorosa, social, ambiental e valores existenciais. Para a Organização Mundial da Saúde, a qualidade de vida reflete a posição da pessoa na vida, no contexto da cultura onde vive seu sistema de valores, objetivos, expectativas, padrões e preocupações ${ }^{10}$, refletindo a compreensão dos indivíduos de que suas necessidades estão sendo satisfeitas ${ }^{11}$.

Diante das considerações expostas, gera-se a hipótese de que os altos níveis de estresse podem propiciar o surgimento de desordens no aparelho estomatognático, apresentando consequências negativas na cavidade oral. Portanto, este estudo tem como objetivo avaliar a prevalência das Lesões Cervicais Não Cariosas (LCNC's) relacionadas ao estresse nos pacientes atendidos na Clínica Escola de Odontologia da Universidade Federal de Campina Grande (UFCG) em 2019.

MATERIAL E MÉTODO

O estudo foi do tipo transversal, observacional, com abordagem indutiva e procedimento comparativo, descritivo, adotando como estratégia de coleta de dados 0 questionário específico Inventário de Sintomas de Estresse de Lipp (ISSL), para avaliar em que nível de estresse se encontrava o paciente, e exame clínico para verificar a presença ou não de LCNC. A presente pesquisa foi submetida à apreciação do comitê de ética em pesquisa das Faculdades Integradas de Patos (FIP) e aprovado sob CAAE: 89367618.7.0000.5181.

A amostra utilizada foi por conveniência e composta por 151 pacientes atendidos na Clínica Escola de Odontologia da UFCG no período de Março a Maio de 2019. Apenas participaram do estudo os pacientes maiores de 18 anos, de ambos os gêneros, e que concordaram espontaneamente em submeterse à pesquisa estando em atendimento na Clínica escola de Odontologia da Universidade Federal de Campina Grande (UFCG). O exame clínico foi realizado com o paciente para analisar a presença ou não de Lesão Cervical Não Cariosa, e em seguida foi feita a entrevista com o questionário. O questionário - Inventário de Sintomas de Stress - ISSL, foi elaborado por Lipp $^{6}$, teve por objetivo fornecer o nível de estresse e possui aplicação breve, de aproximadamente 8 minutos. $O$ questionário apresenta três quadros referentes às fases do estresse. O primeiro é composto de 15 itens que referem-se aos sintomas físicos e psicológicos experimentados nas últimas 24 horas. O segundo é composto de 15 itens que SE referem aos sintomas físicos e psicológicos experimentados na última semana. $\mathrm{E}$ o terceiro quadro, que é composto de 23 itens e está relacionado aos sintomas físicos e psicológicos experimentados no último mês. Alguns dos sintomas se repetem, o que os diferencia são sua intensidade e severidade. Para avaliar o nível de estresse do paciente era analisada a quantidade de assertivas assinaladas pelos pacientes em cada fase. $O$ paciente que relatasse o maior número de assertivas em uma das fases representaria sua condição de saúde relacionada ao estresse. $O$ quadro 1 considerado em fase de alerta, o quadro 2 na fase de resistência, e o quadro 3 na fase de exaustão. Após coletados, os dados da pesquisa foram tabulados.

RESULTADOS

A amostra coletada consistiu de 151 pacientes, sendo 100 do gênero feminino e 51 do gênero masculino, apresentando uma média de idade de 34 anos (Tabela 1).

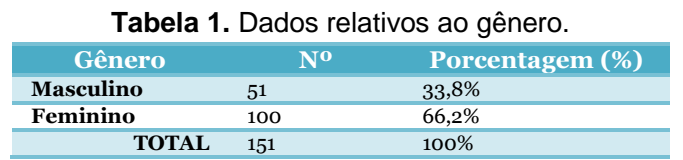

Os participantes foram separados em dois grupos, os que apresentavam lesão cervical não cariosa em pelo menos um elemento dentário e os que não apresentavam a lesão. Em seguida foram classificados em um dos três níveis de estresse presente no inventário de sintomas de estresse de Lipp a partir do maior número de assertivas respondidas em cada fase, segundo o gênero masculino (Tabelas 2 e 3 ) e feminino (Tabelas 4 e 5).

Quando feita a análise separando-se por 
gênero, foi constatado que, dos 51 pacientes do gênero masculino atendidos na Clínica Escola de Odontologia da UFCG, independente de apresentar a LCNC ou não, aproximadamente metade (26 participantes) apresentava-se mais estressado, em fase três correspondente à exaustão, um estresse que perdura por um período de tempo de pelo menos um mês.

Tabela 2. Dados relativos aos pacientes que não apresentavam LCNC e a fase do estresse segundo o gênero masculino.

\begin{tabular}{llll}
\multicolumn{1}{c}{ Fase } & & N $^{\circ}$ & \multicolumn{1}{c}{ Porcentagem (\%) } \\
Fase I & 7 & $20 \%$ \\
\hline Fase II & 10 & $28,6 \%$ \\
\hline Fase III & 18 & $51,4 \%$ \\
\hline & TOTAL & 35 & $100 \%$ \\
\hline
\end{tabular}

Tabela 3. Dados relativos aos pacientes que apresentavam LCNC e a fase do estresse segundo o gênero masculino.

\begin{tabular}{|c|c|c|}
\hline Fase & $\mathbf{N}^{\mathbf{0}}$ & Porcentagem (\%) \\
\hline Fase I & 3 & $18,8 \%$ \\
\hline Fase II & 5 & $31,2 \%$ \\
\hline Fase III & 8 & $50 \%$ \\
\hline TOTAL & 16 & $100 \%$ \\
\hline
\end{tabular}

Tabela 4. Dados relativos aos pacientes que não apresentavam LCNC e a fase do estresse segundo o gênero feminino

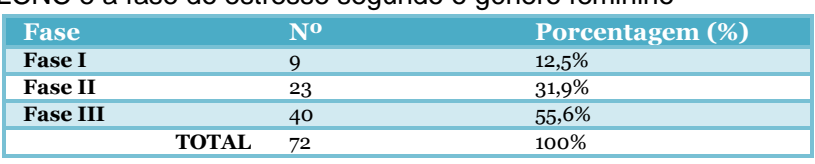

Tabela 5. Dados relativos aos pacientes que apresentavam Lesão Cervical Não Cariosa e a fase do estresse segundo o gênero feminino

\begin{tabular}{|c|c|c|}
\hline Fase & $\mathbf{N}^{\mathbf{o}}$ & Porcentagem (\%) \\
\hline Fase I & 6 & $21,4 \%$ \\
\hline Fase II & 10 & $35.7 \%$ \\
\hline Fase III & 12 & $42,9 \%$ \\
\hline TOTAL & 28 & $100 \%$ \\
\hline
\end{tabular}

Para o gênero feminino foi constatado que das 100 pacientes entrevistadas, apresentando ou não LCNC, mais da metade (52 participantes) apresentava-se mais estressada, também em fase três correspondente à exaustão, perdurando por um período de tempo de um mês.

Dentre as assertivas presentes na Fase I do Inventário de Lipp, correspondente às últimas 24 horas, estavam quatro itens direcionados ao sistema estomatognático (cabeça e pescoço). Os dados foram analisados de acordo com qual dos quatro itens foi assinalado pelo entrevistado, com o gênero e a presença ou não de Lesão Cervical Não Cariosa (Tabelas 6 a 9).

Tabela 6. Dados relativos aos pacientes que não apresentaram Lesão Cervical Não Cariosa, segundo o gênero masculino

\begin{tabular}{|ccc|}
\hline Fase I (cabeça e pescoço) & $\mathrm{N}^{\circ}$ & Porcentagem (\%) \\
\hline Boca seca & 15 & $55,5 \%$ \\
\hline Tensão muscular & 8 & $29,6 \%$ \\
\hline Aperto na mandíbula & 4 & $14,9 \%$ \\
\hline Respiração ofegante (bucal) & 0 & $0 \%$ \\
\hline TOTAL & 27 & $100 \%$ \\
\hline
\end{tabular}

Tabela 7. Dados relativos aos pacientes que apresentaram Lesão Cervical Não Cariosa segundo o gênero masculino

\begin{tabular}{|ccc|}
\hline Fase I (cabeça e pescoço) & No & Porcentagem (\%) \\
\hline Boca seca & 6 & $60 \%$ \\
\hline Tensão muscular & 2 & $20 \%$ \\
\hline Aperto na mandíbula & 2 & $20 \%$ \\
\hline Respiração ofegante (bucal) & 0 & $0 \%$ \\
\hline TOTAL & 10 & $100 \%$ \\
\hline
\end{tabular}

Tabela 8. Dados relativos aos pacientes que não apresentaram Lesão Cervical Não Cariosa segundo o gênero feminino

\begin{tabular}{|c|cc|}
\hline Fase I (cabeça e pescoço) & No & Porcentagem \\
\hline Boca seca & 20 & $35,7 \%$ \\
\hline Tensão muscular & 15 & $26,8 \%$ \\
\hline Aperto na mandíbula & 17 & $30,3 \%$ \\
\hline Respiração ofegante (bucal) & 4 & $7,2 \%$ \\
\hline TOTAL & 56 & $100 \%$ \\
\hline
\end{tabular}

Tabela 9. Dados relativos aos pacientes que apresentaram Lesão Cervical Não Cariosa segundo o gênero masculino

\begin{tabular}{c|cc}
\hline Fase I (cabeça e pescoço) & No & Porcentagem \\
\hline Boca seca & 6 & $25 \%$ \\
\hline Tensão muscular & 12 & $50 \%$ \\
\hline Aperto na mandíbula & 4 & $16,6 \%$ \\
\hline Respiração ofegante (bucal) & 2 & $8,4 \%$ \\
\hline TOTAL & 24 & $100 \%$ \\
\hline
\end{tabular}

Da amostra, 117 assertivas foram marcadas direcionadas ao sistema de cabeça e pescoço, relacionado à saúde bucal presente no questionário na fase I, podendo marcar mais de uma assertiva. A disfunção mais relatada entre os pacientes do gênero masculino, dentre os que apresentavam ou não a lesão, foi a boca seca, com média de $56,7 \%$ das desordens orais. Entre as pacientes do gênero feminino e que não apresentavam LCNC, a disfunção mais relatada também foi a boca seca, com média de $35,7 \%$. E entre as pacientes do gênero feminino que apresentavam LCNC, a tensão muscular foi a disfunção mais relatada, apresentando uma média de $50 \%$. Ficando assim evidente que o estresse com ou sem LCNC tem influência no sistema estomatognático e de cabeça e pescoço.

DISCUSSÃO

No presente estudo foi possível perceber que o maior público da Clínica Escola de Odontologia da UFCG que participou da pesquisa foi o feminino, com 100 entrevistadas $(66,2 \%)$, corroborando com Flumingnan e Sampaio Neto $^{12}$ que determinaram que 0 gênero feminino é predominância na procura do atendimento odontológico. Tortamano et al. $^{13}$ afirmaram que a maior prevalência de mulheres pode ocorrer devido a uma maior preocupação com a saúde e cuidados estéticos ${ }^{14}$. Reis et al. ${ }^{15}$ afirmaram que traçando um perfil dos pacientes atendidos em uma clínica integrada de odontologia, obtiveram o resultado de $67,8 \%$ dos pacientes atendidos sendo mulheres. 0 ministério da saúde afirma que os homens buscam menos por atendimento odontológico nos serviços de saúde e o principal motivo seria o receio da descoberta de alguma doença considerada grave $^{16}$. As diferenças comportamentais poderiam explicar essa discrepância, sendo as mulheres mais propensas a terem cuidados com a sua saúde ${ }^{17}$.

Embora vivam mais do que os homens, as mulheres relatam mais morbidade $e$ problemas psicológicos e utilizam mais serviços 
de saúde ${ }^{18,19}$. Essa predominância do gênero feminino esta em harmonia com a literatura, já que Areias e Guimarães $^{20}$ afirmam que 0 estresse mostra-se mais elevado no gênero feminino do que no gênero masculino. As mulheres apresentam mais estresse pessoal, social e no trabalho e mais fatores psicossociais de risco.

Observou-se que, do total de pacientes entrevistados, mais da metade (78 participantes) encontra-se na fase III, o que significa que $51,7 \%$ dos entrevistados encontram-se no mais alto nível de estresse, o nível de exaustão. Apesar de o estresse acompanhar o homem ao longo do tempo, suas consequências tem se tornado cada vez mais perceptível nos dias atuais ${ }^{21}$ Quando o indivíduo passa por situações de estresse, o organismo busca o equilíbrio homeostático e, quando este não é atingido, surgem as doenças ${ }^{22,23}$.

A literatura atual tem relatado a presença de novos fatores que aumentam o risco para as lesões bucais ${ }^{24,25}$. Muito frequente em grandes centros urbanos, o estresse e a rotina exaustiva têm influenciado no aparecimento de casos de LCNC. Em níveis elevados, como foi observado nos resultados dos questionários aplicados, o estresse pode gerar flexão exagerada nos prismas de esmalte e, consequentemente, às lesões de abfração.

Estudos afirmam ${ }^{26,27}$ que 0 agente etiológico principal da LCNC não é a abrasão pela escovação, mas sim a sobrecarga oclusal nos dentes como resultado da má oclusão e/ou parafunção, associadas às altas concentrações de estresse tensional, que separam os prismas de esmalte e aceleram os processos cervicais não cariosos.

Segundo Silva ${ }^{28}$, o aumento de expectativa de vida da população, indivíduos com maior número de dentes na boca $\mathrm{e}$ estresse associado à vida moderna, fazem com que haja aumento progressivo na prevalência de LCNC tornando-se uma preocupação para a Odontologia.

Esse estilo de vida também favorece o surgimento de sintomas como o apertamento mandibular e a tensão muscular, que estão entre os sintomas relatados pelos pacientes deste estudo, e que favorecem o aparecimento de patologias orais como a DTM, por exemplo.

$O$ estresse emocional pode gerar hiperatividade muscular, caracterizando 0 chamado bruxismo ou apertamento dental ${ }^{29}$. O bruxismo do sono é caracterizado por movimentos estereotipados e periódicos, sendo que o sintoma mais importante é o ranger dos dentes, com ruídos característicos semelhantes ao atrito de "granito contra granito". Esse sintoma geralmente é relatado pelos familiares e decorrentes da contração rítmica dos músculos masseteres durante o sono. A dor é um sintoma frequente ${ }^{30}$.

Segundo Garcia $^{29}$, tanto o estresse quanto a oclusão têm participação diferente na ocorrência da DTM, dependendo da capacidade adaptativa do paciente. Esta diferença é explicada pelos distintos graus de tolerância fisiológica ao estresse. $O$ efeito da hiperatividade muscular desenvolvida a partir desse estado emocional exacerbado afetará a ATM. Assim, quando um componente emocional está associado a um fator físico, como a alteração oclusal, a liberação das tensões pelo aparelho estomatognático produz sintomas de dor e disfunção.

Neste estudo não houve disparidade quanto ao nível de estresse, visto que os dois gêneros analisados foram classificados em sua maioria na fase III, onde está o maior nível de estresse, a fase de exaustão.

CONCLUSÃO

Diante do exposto, explana-se que o estresse pode propiciar o surgimento de desordens no aparelho estomatognático, apresentando consequências negativas na cavidade oral, uma vez que se constatou a presença de mais da metade dos participantes, que apresentavam LCNC, na fase de exaustão, a fase III do Inventário de Sintomas de Stress de Lipp (ISSL). Do mesmo modo, metade das pacientes do gênero feminino, e que apresentavam LCNC, apresentaram o sintoma tensão muscular como o mais assinalado. Ainda, são necessários mais estudos para identificar de fato a relação da LCNC com a presença e ausência do estresse.

\section{REFERÊNCIAS}

1. Bartlett DW, Shah PA. Critical review of noncarious cervical (wear) lesions and the role of abfraction, erosion, and abrasion. J Dent Res. 2006;85(4):306-12.

2. Bonfim RA, Crosato E, Mazzilli LEN, Frias AC. Prevalence and risk factors of non-carious cervical lesions related to occupational exporuse to acid mists. Braz Oral Res. 2015;29(1):1-8.

3. Molena CCL, Rapoport A, Rezende CP, Queiroz CM, Denardin OVP. Relação entre lesões cervicais não cariosas e hábitos. Rev bras cir cabeça pescoço. 2008;37(4):206-11.

4. Amaral SM, Abad EC, Maia KD, Weyne S, Oliveira MPRPB, Tunãs ITC. Not carious lesions: the challenge of the multidisciplinary diagnosis. Arq Int Otorrinolaringol. 2012;16(1):96-102. 
5. Ribeiro RP, Martins JT, Marziale MHP, Robazzi MLCC. O adoecer pelo trabalho na enfermagem: uma revisão integrativa. Rev Esc Enferm USP. 2012;46(2):495-504.

6. Sardá JRJJ, Legal EJ, Jablonski Jr SJ. Estresse: conceitos, métodos, medidas e possibilidades de intervenção. São Paulo: Casa do Psicólogo; 2004.

7. Lipp MEN. Mecanismos neuropsicológicos do stress: teoria e aplicações clínicas. São Paulo: Casa do Psicólogo; 2003.

8. Rees JS, Jagger DC. Abfraction lesions: myth or reality? J Esthet Restor Dent. 2003; 15(5):263-71.

9. Xhonga FA. Bruxism and its effect on the teeth. J Oral Rehabil. 1977;4(1):65-76.

10. Pedro A, Ribeiro J, Soler G, Bugdan A. Qualidade de vida em mulheres com incontinência urinaria. SMAD, Rev. Eletrônica Saúde Mental Álcool Drog. 2011;7(2):63-70.

11. Rigoni ACC, Silva LF, Silva TP, Fernandes BPBPF, Silva CL. Relações entre a educação física escolar, as práticas corporais e a qualidade de vida. Rev CPAQV. 2017;9(1):1-9.

12. Flumignan JDP, Sampaio Neto LF. Atendimento odontológico em unidades de emergência: caracterização da demanda. Rev Bras Odontol. 2014;71(2):124-29.

13. Tortomano IP, Leopoldino VD, Borsatti MA, Sarti Penha S, Buscariolo IA, Costa CG et al. Aspectos Epidemiológicos e Sociodemográficos do setor de urgência da faculdade de odontologia da universidade de são Paulo. RPG Rev Pós Grad. 2007;13(14): 299-306.

14. Woodwell DA, Cherry DK. National Ambulatory Medical Care Survey: 2002 summary. Adv Data. 2004;(346):1-44.

15. Reis S, Santos L, Leles C. Clínica Integrada de Ensino Odontológico: Perfil dos Usuários e Necessidades Odontológicas. ROBRAC. 2011; 20(52):46-51.

16. Gomes R, Nascimento EF, Araújo FC. Por que os homens buscam menos os serviços de saúde do que as mulheres? As explicações de homens com baixa escolaridade e homens com ensino superior. Cad saúde pública. 2007; 23(3):565-74.

17. Martins RJ, Garcia AR, Garbin CA, Sundefeld MLMM. Associação entre classe econômica e estresse na ocorrência da disfunção temporomandibular. Rev bras epidemiol. 2007; 10(2):215-22.

18. Macintyre S, Hunt K, Sweeting H. Gender differences in health: are things really as simple as they seem? Soc Sci Med. 1996;42(4): 617-24.

19. Bird CE, Rieker PP. Gender matters: an integrated model for understanding men's and women's health. Soc Sci Med. 1999;48(6): 745-55.
20. Areias MEQ, Guimaraes LAM. Gênero e estresse em trabalhadores de universidade pública do estado de São Paulo. Psicol estud. 2004;9(2):255-62.

21. Verbrugge LM. The twain meet: empirical explanations of sex differences in health and mortality. J Health Soc Behav. 1989;30(3):282304.

22. Selye $H$. The stress of life. New York: Mc Graw Hill; 1984

23. Lipp MEN. Emotional stress: contribution from internal and external stressors. Rev psiquiatr clín. 2001;28(6):347-49.

24. Kina M, Vilas Boas TP, Tomo S, Fabre AF, Simonato LE, Boer NP et al. Lesões cervicais não cariosas: protocolo clínico. Arch Health Invest. 2015;4(4):21-8.

25. Cavalcante LPA, Cruz JHA, Figueiredo CHMC, Medeiros LADM, Penha ES, Oliveira Filho AA et al. Avaliação do nível de estresse em pacientes com lesão cervical não cariosa atendidos na Clínica de Odontologia da UFCG. Arch Health Invest. 2019;8(9):479-83.

26. Kliemann C. Lesões cervicais não cariosas por abrasão (escovação traumática). J bras clin odontol integr. 2002; 6(33):204-9.

27. Pegoraro LF, Scolaro JM, Conti PC, Telles D, Pegoraro TA. Noncarious cervical lesions in adults. Prevalence and occlusal aspects. J Am Dent Assoc. 2005;136(12):1694-700.

28. Silva FML. Lesões cervicais não cariosas: Prevalência, severidade e correlação com fatores Etiológicos [dissertação]. Uberlândia: Faculdade de Odontologia, UFU; 2006.

29. Garcia AR. Contribuição para o diagnóstico, prognóstico e plano de tratamento de pacientes com disfunção e/ou desordens temporomandibulares: avaliação clínica, radiográfica e laboratorial [tese]. Araçatuba: Faculdade de Odontologia de Araçatuba, UNESP; 1997.

30. Alóe F, Gonçalves LR, Azevedo A, Barbosa RC. Bruxismo durante 0 sono. Rev Neurociências. 2003;11:4-17.

\section{CONFLITO DE INTERESSES}

Os autores declaram não haver conflitos de interesse

AUTOR PARA CORRESPONDÊNCIA

\section{José Henrique de Araújo Cruz}

Rua Paulo Diogenes, número 57, Centro, 59990 - 000 Rafael Fernandes - RN, Brasil Telefone: (83) 99625-0125.

E-mail: henrique_araujo1992@hotmail.com 